\title{
Expressed Sequence Tag-Simple Sequence Repeat (EST-SSR) Marker Resources for Genetic Diversity Analysis in Different Varieties of Roses (Rosa spp.)
}

\author{
Tanay Joshi*, Santosh Kumar, Mohan Bhimte and Lakhapati Singh \\ Department of International Cooperation, Research Institute of Organic \\ Agriculture FiBL, Switzerland \\ *Corresponding author
}

\begin{abstract}
A B S T R A C T
Characterization and quantification of diversity in plant genetic resources were important to identify cultivars and clones, decipher relationships including parentages, and to efficiently manage germplasm collections. The present studies was undertaken to find out

\section{Keywords}

EST-SSR, Rosa spp, Dendrogram, Polymorphic information content

\section{Article Info}

Accepted:

15 April 2020

Available Online:

10 May 2020 genetic diversity among twenty-one genotypes of rose (Rosa species) using EST-SSR markers. Out of the total 35 EST-SSR primers screened, a set of 12 primers showed polymorphism. PCR amplification yielded a total of 31 amplified products with a range 2 and 4 bands per primer (amplified size 90bp -550bp). The polymorphic information content (PIC)value of the primers ranged from (0.22- 0.96) with Highest PIC and Marker Index (MI) was recorded by primers RS-18 followed by Primer RS-30 and RS-10. Hence, primer RS-18 and Primer RS-30 were found to be highly informative. Jaccard's similarity coefficient ranged from 0.143 to 0.923 . Minimum similarity was observed between the genotype (Lady X) and (Happiness) (0.143). The similarity coefficient used to construct a dendrogram using UPGMA cluster analysis. The dendrogram grouped the twenty-one rose genotypes into three distinct clusters. Therefore, from this study the genotypes (Lady X) and (Happiness) (0.143) possesses diverse genetic background which can also be used as parent for further hybridization programme.
\end{abstract}

\section{Introduction}

Rose is one of the most commonly cultivated ornamental plants in the world. Rose production and demand for cut flower, garden and potted plants, is increasing worldwide. It is said that rose came first and man afterwards. Fossils of the rose found in Oregon and Colorado (USA) are estimated to be more than thirty million years old (Fairbrother, 1965).

Rose (Rosa spp.) has a large genome size and is one of the most commercially cultivated ornamental plants in the world (Rajeshbabu et al., 2014). Modern rose cultivars are generally triploid or tetraploid hybrids derived from 7 10 wild diploid rose species and a few 
tetraploid species. The genus Rosa consists of about 200 species and thousands of cultivars that are widely distributed in Europe, Asia, Middle East, and North America with the greatest diversity of species found in western China (Phillips and Rix, 1988; Nilsson, 1997). More than 150 species have already been catalogued (Kruessmann, 1981; Cairns, 1993; Quest-Ritson and Quest-Ritson, 2003). The exact numbers of the rose cultivars are unknown, whereas the number is estimated at more than 20000 rose cultivars in the world (Rajapakse et al., 2001; Kim et al., 2003). Also, only 11 out of 200 Rosa species have contributed to the origin of modern cultivars. Flower symbolizes beauty, purity, tranquility and divinity and offering of flower is a sign of reverence. Rose is used as cut and loose flowers. They are used in making perfumes, essential oils, rose water and other cosmetics. Apart from these, roses are used to make medicine and have soothing effects in mind and body. As a result, rose cultivars with better characteristics and good quality are pretty much in demand in floriculture industry.

Thus, apart from good quality blooms, the availability of quality planting material is also a major concern of rose breeding in India. With the development of highly informative and technically simple PCR based markers like RAPDs, ISSRs, AFLPs and microsatellites, the diversity studies and marker-based analysis of commercially important traits like; color, size, fragrance in rose have gained momentum. Over the last few decades plant genomics has been studied extensively bringing about a revolution in this area.

Today molecular markers play an essential role in all aspects of plant breeding, ranging from the identification of the genes responsible for the desired traits to the management of backcrossing programmes.
Genetic diversity is one of the most important factors for crop improvement. Modern breeding processes have considerably narrowed the variation of important traits. Therefore, it is important to investigate genetic diversity of germplasm to access its usefulness for breeding programmes. Molecular markers are a promising tool for evaluating the genetic diversity among plant materials, as the phenotype and physiological markers are not accurate enough and often depend on environmental conditions. Genepool studies are important in any crop because a wide range of variability always provides more possibility of selecting desired types (Vavilov, 1951).

The present study mainly focuses around PCR based SSR, EST technique. A little work so far has been done on genetic relatedness studies. Therefore, this study was under taken to see molecularly characterize, inter-genetic variability and genetic relatedness studies in various types of rose cultivars having diverse nature and origin.

\section{Materials and Methods}

\section{Plant material}

The experimental material for the present investigation comprised of 21 rose varieties (Table 1) was collected from Rose Germplasm Block at the Model Floriculture Centre, Govind Ballabh Pant University of Agriculture and Technology, Pantnagar and molecular assessment work was carried out at National Research Centre for DNA Fingerprinting at National Bureau of Plant Genetic Resources, New Delhi.

\section{DNA extraction and quantification}

Genomic DNA was to be isolated from young leaves samples that were collected from Germplasm Block was stored under frozen 
conditions $\left(0-4^{0} \mathrm{C}\right)$. Total DNA was isolated according to the protocol described by CTAB extraction methods of (Murray and Thompson, 1980) modified by (SaghaiMaroof, 1984), (Doyle and Doyle 1990) from the fresh leaves with minor modification. Further, crude DNA samples were purified twice with an equal volume of chloroform: isoamyl alcohol (24:1) and precipitated by using $1 / 10$ volumes of $3 \mathrm{M}$ sodium acetate (PH 5.6) and 2.5 volumes of $95 \%$ chilled ethanol. DNA concentration was estimated by agarose gel electrophoresis $(0.8 \%$ gel $)$ containing $0.5 \mu \mathrm{g} \mathrm{mL}^{-1}$ ethidium bromide) using known concentration (50 ng) of uncut lambda DNA as standards. The purified rose genomic DNA was diluted in sterile double distilled water to make a concentration of 20 ng $\mu \mathrm{L}^{-1}$ for each sample and stored at $4^{0} \mathrm{C}$.

\section{Microsatellites marker development}

National Centre for Biotechnology Information (NCBI) was recognized as a national resource for molecular biology information in 1988, as it creates public databases, develops software for analyzing genomic data and much more, so as to have a better understanding of molecular development. Out of a total of, 5563 EST sequences, of Rosa hybrida available at the website of NCBI. 1-2200 sequences for developing EST- SSR markers were mined from the database and were, downloaded. These sequences were derived from the rose petals of the cultivars: Fragrant cloud and Black baccara (r). These sequences were then, programmed using web software for the development of microsatellite marker named as WEBSAT (Martins et al., 2009). This software is accessible through the internet, requiring no programme installation. WEBSAT was written in PHP and Java script, making use of Ajax techniques. Its input can be either individual sequence, in raw or in FASTA format or a group of sequences in a multi- FASTA format. This software requires two things: one is an SSR finder programme and a primer designer programme. WEBSAT uses TROLL as its SSR finder Programme due to its simplicity and efficiency. PRIMER 3 was chosen as the primer design programme since; it is widely used and provides a rich set of, easily modifiable parameters.

Using this software and the above stated programmes, 84 primers were developed out of which 35 primers were ordered to be synthesized by Ocimum Biosolutions.

\section{PCR amplification and electrophoresis}

In present investigation, a set of 12 EST-SSR primer were used for PCR amplification in 21 rose genotypes (Table 2).PCR amplification was performed in $25 \mu \mathrm{l}$ reaction volumes containing $20 \mathrm{ng} \mu \mathrm{l}-1$ genomic DNA, $2.5 \mu \mathrm{l}$ 10X PCR buffer, $1.25 \mu \mathrm{l}$ of $17.5 \mathrm{mM} \mathrm{MgCl}_{2}$, $0.5 \mu \mathrm{l}$ of $10 \mathrm{mM}$ dNTPs (each of dATP, dGTP, dCTP and dTTP), $2.5 \mu 1$ of 10 pmole/ $\mu 1$ primer and 5U/ $\mu 1$ Taq DNA Polymerase in $200 \mu 1$ PCR tube. PCR profile was consisting initial denaturation step of $3 \mathrm{~min}$ at $94^{\circ} \mathrm{C}$ afterward 35 cycles of $30 \mathrm{sec}$ at $94^{\circ} \mathrm{C}$ for DNA denaturing, $30 \mathrm{sec}$ for annealing at $55^{\circ} \mathrm{C}$, and $1 \mathrm{~min}$ for DNA extension at $72^{\circ} \mathrm{C}$ with a final extension for $4 \mathrm{~min}$ at $72^{\circ} \mathrm{C}$ and then held at $4^{\circ} \mathrm{C}$ till electrophoresis.

\section{Gel electrophoresis}

After completion of PCR amplification reactions, $2 \mu$ of loading dye (6X) was added to each PCR tube. $1.4 \%$ agarose gel stained with ethidium bromide $(10 \mathrm{mg} / \mathrm{ml})$ was prepared and the contents of the PCR tubes were loaded in to gel wells. Electrophoresis was carried out at $90 \mathrm{~V}$ for $4-5$ hours. The resolved amplification products were visualized by illumination under UV light at $302 \mathrm{~nm}$ wave length and photographed using gel documentation unit. 


\section{Scoring and data analysis}

For all the genotypes, EST- SSR bands were scored as present (1) or absent (0). Only those fragments with medium or high intensity were taken in account. Fragments with the same mobility on the gel but with different intensities were not distinguished from each other. Jaccard's similarity coefficient values for each pairwise comparison between genotypes were calculated and a similarity coefficient matrix was constructed. This matrix was subjected to unweighted pairgroup method for arithmetic averages analysis (UPGMA) to generate a dendrogram using average linkage procedure. Jaccard's similarity coefficient analysis and dendrogram construction were carried out using NTSYS- PC version 1.7 (Rohalf, 1993).

\section{Results and Discussion}

\section{Molecular fingerprinting by EST-SSR markers}

Characterization and quantification of diversity in plant genetic resources are important to identify cultivars and clones, decipher relationships including parentages, and to efficiently manage germplasm collections. Several important qualitative and quantitative rose traits have been located in different rose maps Debener (1999); Debener and Mattiesch (1999); Crespel et al., (2003); Dugo et al., (2005); Yan et al., (2005); Zhang et al., (2006). EST- SSR markers developed in this and other studies will provide tools for the establishment of a consensus linkage map for roses that combine traits and markers in the various maps. One of the major goals of this study was to develop new easily transferable EST- SSR markers in rose. The rose cultivars studied for EST- SSR characterization included 10 hybrid teas, 5 floribundas that belong to genus Rosa, species hybrida and other 6 cultivars selected primarily were oil content varieties and belong to genus Rosa and species damascene.

In present study a total of 35 new rose SSR markers were generated from this study, from EST sequences. Out of these, 12 EST- SSRs have displayed polymorphism. The remaining 23 SSRs, did not show any polymorphism and gave rise to indistinguishable PCR products, they might be useful in other rose populations and studies. Similarly, Akond et al., (2012) screen total 28 primer, out of which 15 primers selected which showed polymorphism among four genotypes (NA65113, 'Golden Horizon', hybrid 3 and NA7008) for further analysis.

PCR amplification of the DNA isolated from 21 genotypes yielded a total of 31 amplified products which varied between 2 and 4 with an average of 2.58 bands per primer. The size of clearly detectable amplified EST- SSR PCR fragments ranged from $90 \mathrm{bp}$ to $550 \mathrm{bp}$. Maximum number of alleles were revealed by primer RS-18 (4) and RS-30, (4). The polymorphic information content (PIC) value of the primers ranged from (0.22- 0.96) with the average value of $(0.45)$ per primer. Allele diversity or PIC was calculated for all EST SSR markers used in this study. Highest PIC was recorded by primers RS-18, (0.93) followed by Primer RS-30 (10.29) and RS$10(0.53)$ and it was found to be lowest by primer RS-12 (0.22) and primer RS-23 (0.24). The higher the PIC value, the more informative is the EST-SSR marker. Hence, primer RS-18 and Primer RS-30 were found to be highly informative (Figure 3). Similar result also found by Panwar et al., (2015); Ograş et al., (2017).

Marker index (MI) is the statistic used to calculate the overall utility of a marker system and is the product of Polymorphism information content (PIC) and Effective multiplex ratio (EMR). EMR for all the primers was found to be 12 . 
Table.1 Experimental Material: 21 rose varieties

\begin{tabular}{|c|c|c|c|}
\hline Sr. no & Cultivar & & Pedegree and Source \\
\hline 1 & Hapiness & (HT) & $\begin{array}{l}\text { (Rome glory } \times \text { Tassin }) \times[\text { Charles P. Kilham } \times \\
(\text { Charles P Kilham } \times \text { Capucine Chambard }]\end{array}$ \\
\hline 2 & Kiss of Fire & (HT) & Lavena Roses cavriglia \\
\hline 3 & Superstar & (HT) & $($ Seedling $\times$ Peace $) \times($ Seedling $\times$ Alpine Glow $)$ \\
\hline 4 & Mirnalani & (HT) & Pink Parfait $\times$ Christian Dior \\
\hline 5 & Lady X & (HT) & Seedling $\times$ Simone \\
\hline 6 & Eiffel Tower & (HT) & First Love $\times$ Seedling \\
\hline 7 & Avon & (HT) & Nocturne $\times$ Chrysler Imperial \\
\hline 8 & Swarthmore & (HT) & (Independence $\times$ Happiness $) \times$ Peace \\
\hline 9 & Abhisarika & (HT) & Induced Mutant $\times$ Kiss of Fire \\
\hline 10 & President & (HT) & - \\
\hline 11 & Delhi Prince & (FL) & IARI \\
\hline 12 & Ice Berg & $(\mathrm{FL})$ & Robinhood $\times$ Virgo \\
\hline 13 & Pink Delight & (FL) & - \\
\hline 14 & Laher & (FL) & IARI \\
\hline 15 & Nimish & $(\mathrm{FL})$ & - \\
\hline 16 & Noorjahan & $(\mathrm{OC})$ & Sweet Afton $\times$ Crimson Glory \\
\hline 17 & Rani Sahiba & $(\mathrm{OC})$ & CIMAP Selection \\
\hline 18 & Gruss n Tepliz & $(\mathrm{OC})$ & $\begin{array}{l}{[((\text { Sir Joseph Paxton } \times \text { Fellenberg }) \times \text { Papa Gontier })} \\
\times \text { Gloredes Rosomanes }]\end{array}$ \\
\hline 19 & Himroz & $(\mathrm{OC})$ & IHBT \\
\hline 20 & Jawala & $(\mathrm{OC})$ & IHBT \\
\hline 21 & Chati Gulab & $(\mathrm{OC})$ & CIMAP Selection \\
\hline
\end{tabular}

Table.2 Polymorphism exhibited by EST- SSR primers in 21 Rose cultivars

\begin{tabular}{|c|c|c|c|c|c|}
\hline Primer & Repeat Motif & No. of Alleles & Observed Size & PIC/DI & MI \\
\hline RS- 5 & (AG) 11 & 2 & $185-190$ & 0.36 & $\mathbf{4 . 3 5}$ \\
\hline RS- 9 & (AG) 15 & 3 & $200-300$ & 0.41 & $\mathbf{4 . 8 9}$ \\
\hline RS- 10 & (AG) 23 & 3 & $345-355$ & 0.53 & $\mathbf{6 . 3 6}$ \\
\hline RS- 12 & (AGC) 7 & 2 & $450-550$ & 0.22 & $\mathbf{2 . 6 1}$ \\
\hline RS- 13 & (ATCT)7 & 2 & $200-210$ & 0.45 & $\mathbf{5 . 4 5}$ \\
\hline RS- 15 & (CT)11 & 2 & $140-160$ & 0.33 & $\mathbf{3 . 9 1}$ \\
\hline RS- 16 & (CT)12 & 2 & $145-148$ & 0.50 & $\mathbf{5 . 9 4}$ \\
\hline RS- 18 & (CT) 15 & 4 & $90-120$ & 0.93 & $\mathbf{1 1 . 1 6}$ \\
\hline RS- 21 & (GA) 13 & 2 & $450-550$ & 0.36 & $\mathbf{4 . 3 5}$ \\
\hline RS- 23 & (GA) 20 & 2 & $350-360$ & 0.24 & $\mathbf{2 . 9 3}$ \\
\hline RS- 26 & (TC)12 & 2 & $360-375$ & 0.31 & $\mathbf{3 . 7 0}$ \\
\hline RS- 30 & (TCT)6 & 4 & $400-500$ & 0.86 & $\mathbf{1 0 . 2 9}$ \\
\hline Total & ------ & ------- & $\mathbf{5 . 5 0}$ & $\mathbf{6 5 . 9 4}$ \\
\hline Average & ------- & $\mathbf{0 . 4 5}$ & $\mathbf{5 . 4 9}$ \\
\hline
\end{tabular}


Int.J.Curr.Microbiol.App.Sci (2020) 9(5): 1721-1730

\begin{tabular}{|c|c|c|c|c|c|c|c|c|c|c|c|c|c|c|c|c|c|c|c|c|}
\hline 1 & 2 & 3 & 4 & 5 & 6 & 7 & 8 & 9 & 10 & 11 & 12 & 13 & 4 & 15 & 16 & 17 & 18 & 19 & 20 & 21 \\
\hline 0.412 & & & & & & & & & & & & & & & & & & & & \\
\hline 0.353 & 0.389 & & & & & & & & & & & & & & & & & & & \\
\hline 0.412 & 0.4 & 0.786 & & & & & & & & & & & & & & & & & & \\
\hline 0.143 & 0.474 & 0.389 & 0.333 & & & & & & & & & & & & & & & & & \\
\hline 0.278 & 0.588 & 0.6 & 0.421 & 0.688 & & & & & & & & & & & & & & & & \\
\hline 0.6 & 0.474 & 0.471 & 0.474 & 0.4 & 0.5 & & & & & & & & & & & & & & & \\
\hline 0.333 & 0.474 & 0.667 & 0.474 & 0.556 & 0.8 & 0.556 & & & & & & & & & & & & & & \\
\hline 0.278 & 0.588 & 0.6 & 0.421 & 0.588 & $0.85 T$ & 0.5 & 0.8 & & & & & & & & & & & & & \\
\hline 0.333 & 0.556 & 0.563 & 0.556 & 0.556 & 0.688 & 0.647 & 0.75 & 0.638 & & & & & & & & & & & & \\
\hline 0.353 & 0.688 & 0.5 & 0.5 & 0.5 & 0.733 & 0.588 & 0.388 & 0.857 & 08 & & & & & & & & & & & \\
\hline 0.375 & 0.529 & 0.643 & 0.625 & 0.444 & $0.86 \mathrm{~T}$ & 0.625 & 0.525 & 0.637 & 0.733 & 0.786 & & & & & & & & & & \\
\hline 0.333 & 0.556 & 0.563 & 0.556 & $0.4 \bar{i} 4$ & 0.688 & 0.556 & 0.347 & 0.638 & 0.75 & 0.8 & 0.857 & & & & & & & & & \\
\hline 0.353 & 0.588 & 0.6 & 0.588 & 0.5 & 0.733 & 0.588 & 0.388 & 0.733 & 08 & 0.857 & 0.923 & 0.929 & & & & & & & & \\
\hline 0.375 & 0.529 & 0.438 & $0 . \angle 44$ & 0.368 & 0.563 & 0.625 & 0.529 & 0.553 & 0.625 & 0.667 & 0.6 & 0.625 & 0.667 & & & & & & & \\
\hline 0.313 & 0.316 & 0.375 & 0.389 & 0.389 & 0.412 & 0.316 & 0.389 & 0.412 & 0.471 & 0.5 & 0.533 & 0.563 & 0.6 & 0.438 & & & & & & \\
\hline 0.25 & 0.353 & 0.313 & 0.353 & 0.353 & 0.375 & 0.278 & 0.353 & 0.375 & 0.438 & 0.467 & 0.4 & $0 .<38$ & 0.467 & 0.4 & 0.538 & & & & & \\
\hline 0.294 & 0.444 & 0.211 & 0.238 & 0.3 & 0.316 & 0.444 & 0.3 & 0.316 & 0.444 & 0.389 & 0.333 & 0.368 & 0.389 & 0.5 & 0.278 & 0.313 & & & & \\
\hline 0.211 & 0.286 & 0.2 & 0.227 & 0.421 & 0.368 & 0.35 & 0.35 & 0.338 & 0.5 & 0.444 & 0.389 & $0 .<21$ & 0.444 & 0.389 & 0.6 & 0.375 & 0.471 & & & \\
\hline 0.222 & 0.2 & 3.15 & 0.2 & 0.333 & 0.278 & 0.333 & 0.263 & 0.278 & 0.412 & 0.353 & 0.294 & 0.333 & 0.353 & 0.375 & 0.5 & 0.333 & 0.467 & 0.917 & & \\
\hline 0.211 & 0.316 & 0.263 & 0.316 & 0.389 & 0.412 & 0.316 & 0.389 & 0.412 & 0.471 & 0.5 & 0.438 & 0.471 & 0.5 & 0.438 & 0.571 & 0.5 & 0.438 & 0.846 & 0.769 & 0.481 \\
\hline
\end{tabular}

Figure.1 EST-SSR Similarity Matrices.

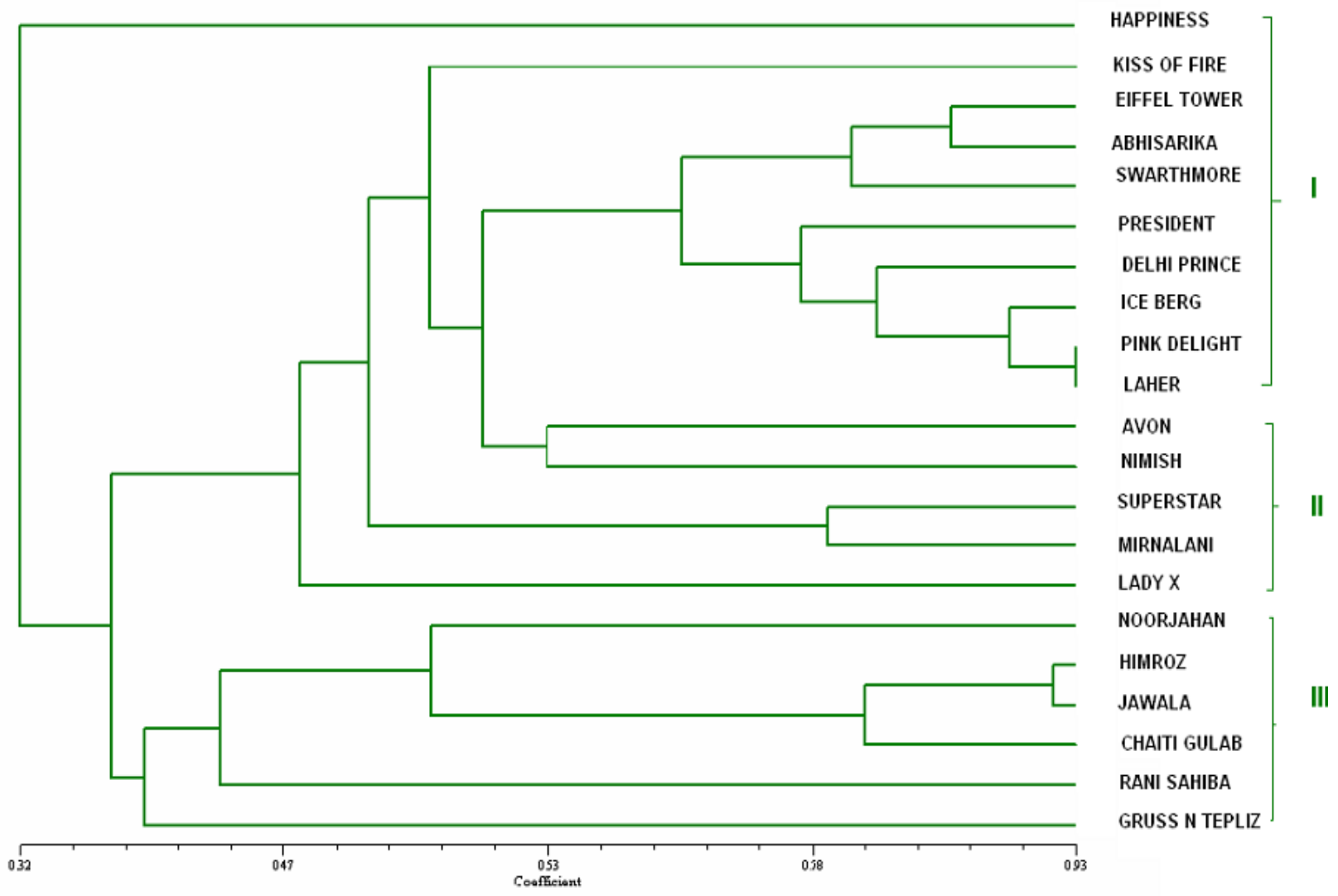

Figure.2 UPGMA clustering pattern revealed by the 21 Rose Genotype using EST - SSR data. 


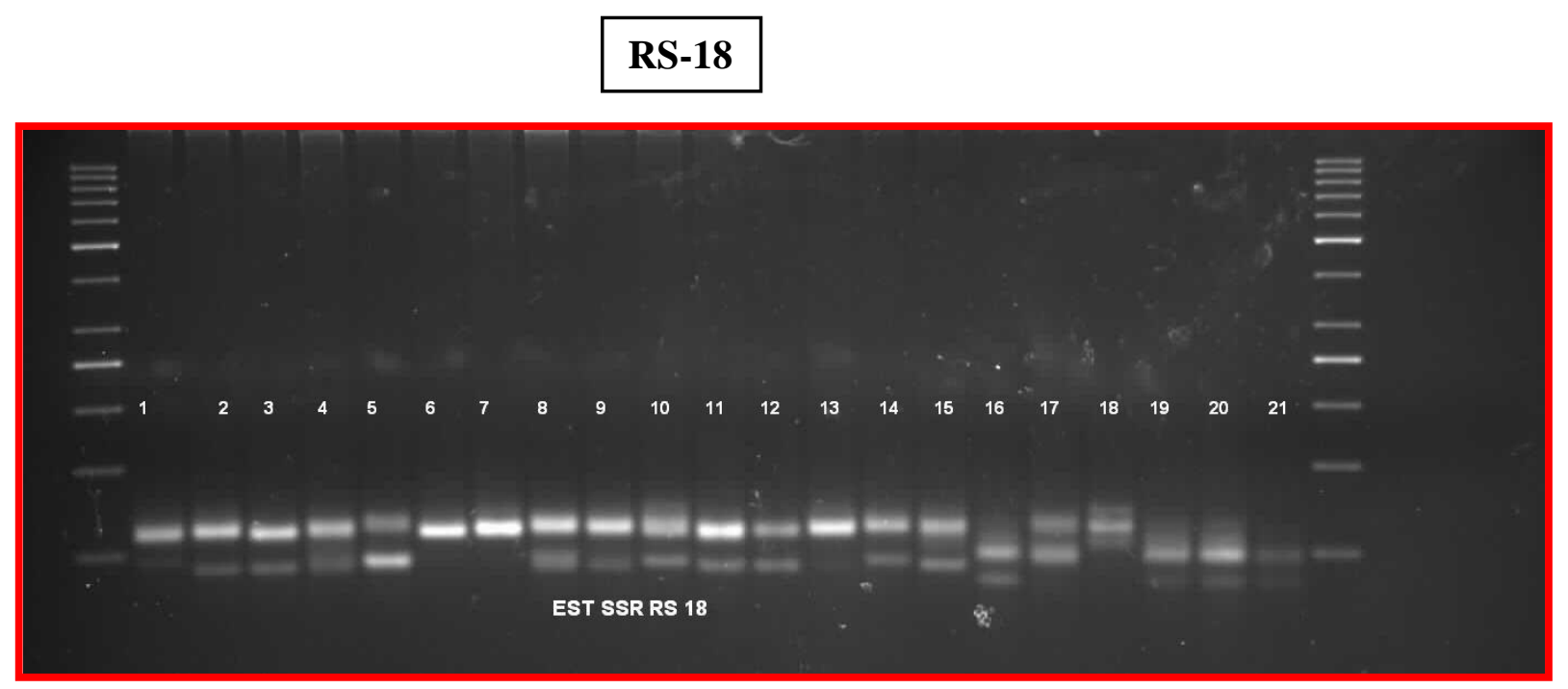

RS-10

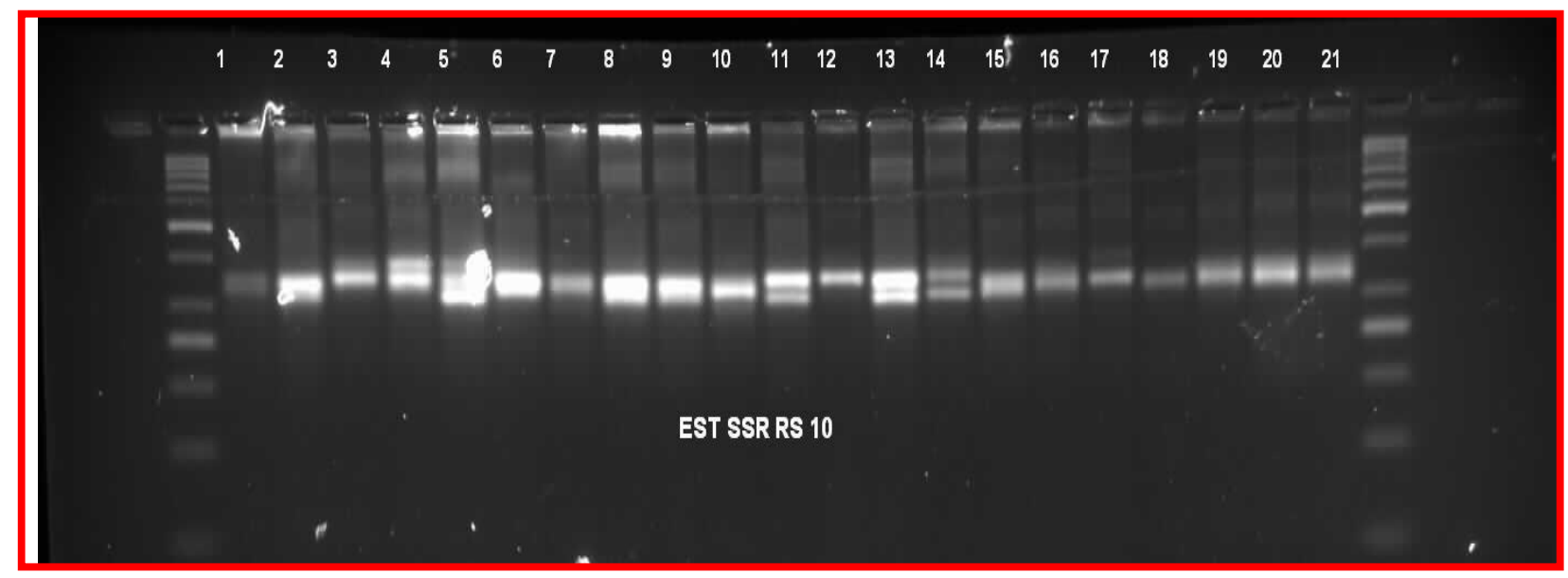

Figure.3 Amplification profile of 21 Rose genotypes obtained by Primer RS-18 and RS-10.

L- 1 KB ladder, 1-Hapiness, 2-Kiss of Fire, 3-Superstar, 4-Mirnalani, 5-Lady X, 6-Eiffel Tower, 7-Avon, 8-Swarthmore, 9-Abhisarika, 10-President, 11-Delhi Prince,12-Ice Berg, 13-Pink Delight, 14-Laher, 15-Nimish, 16-Noorjahan, 17-Rani Sahiba, 18-Gruss n Tepliz, 19-Himroz, 20-Jawala, 21-Chati Gulab.Rose genotypes.

The primers $\mathrm{RS}-12$, and $\mathrm{RS}-23$, had low marker indices (0.22 and 0.24 , respectively), while the other primers RS-18, (11.16) followed by RS-30, (10.29) showed high MI values. Average MI for the 12 primer used in this study was 5.49 (Table 2).
Genetic diversity and relationship based on EST-SSR markers

Development of desired variety requires assessment of genetic diversity as the basis of breeding. Hybridization among diverse genotypes may create a new gene pool with 
specific traits (Singh and Shukla, 1998). Hybridization can be carried out among the genotypes that belong to distance clusters. Thus, a wide range of seggregants could be obtained for desired characters (Aminul Islam et al., 2016). According to the literature, the breeding material could be selected which having highest genetic difference to improve new varieties (Singh, 1991). It is stated that the crossing of highly statistically distant genotypes from the clusters leads to variations among the seggregants (De et al., 1992). These distant genotypes could be used in breeding programs for obtaining a wide spectrum of variation.

In present study, Genetic similarity between 21 rose genotypes was determine on the basis of Jaccard's pairwise similarity coefficient using EST-SSR amplification data. Similarity coefficient ranged from 0.143 to 0.923 with a mean value 0.481 (Figure 1). Minimum similarity was observed between the genotype (Lady X) and (Happiness) (0.143) followed by genotype (Jawala) and (Superstar) (0.150). From this investigation it was suggested that the germplasm accessions which had least similarity percentage between them can be used as a potential parent in hybridization programme to get heterotic F1 hybrids. Hence to improve desirable traits in superior varieties these accessions can be used as parents for hybridization programme.

Based on UPGMA (Unweighted Pair Group Method with Arithmetic Mean), The clustering pattern obtained by EST-SSR analysis clearly distinguished allthe 21 genotypes were broadly divided into three clusters (Figure 2).

In which cluster I included ten genotypes, (Happiness), (Eiffel tower), (Kiss of Fire), (Abhisarika), (Swarthmore), (President), (Delhi prince), (Iceberg), (Pink delight), (Laher), which is obviously because all of them belong to same species. cluster II included five genotypes, (Avon), (Nimish), (Superstar), (Mrinalini), (Lady X), which is again from the same species and cluster III included six genotypes (Noorjahan), (Himroz), (Jwala), (Chatigulab), (Ranisahiba) and (Gruss $n$ Tepliz) because of an obvious reason that all of them belong to same species damascena and come from the same set of varieties that belong to damaskroses. They may have clustered together as they belong to same genus and species i.e. Rosa hybrida. again, Cultivar Abhisarika and Kiss of Fire were found to a sub cluster in Cluster- I because Abhisarika is the mutant of kiss of Fire Sasikumar et al., (2007). Interestingly, all the cultivars that belong to Genus Rosa and species damascena, Damask Rose Kaur et al., (2007) cluster together to for Cluster- III as all of them are known for the high oil percentage. Baydar et al., (2004) also reported that there is very little genetic variation among $R$. damascena plants grown in Turkey. Thus, the genotypes from the diversified clusters can be used as parents for hybrid and varietal development programme.

In conclusion, this genetic diversity evaluation concluded that all the characters under study showed significant differences among the accessions. Potential donor with highest mean value can be exploited for further improvement in breeding programme. From this study, the genetically diversified genotypes (Lady X) and (Happiness) (0.143) followed by genotype (Jawala) and (Superstar) (0.150) which were identified can also be used as a potential parent in hybridization programme to get heterotic F1 hybrids.

\section{References}

Akonda, M., S. Jinb and Wanga, X. 2012. Molecular characterization of selected wild species and miniature roses based 
on SSR markers. Scientia Horticulturae, 147 (2012) 89-97.

Aminul Islam, A.K.M., N. Anuar, Z. Yaakob and Osman, M. 2016. Genetic diversity among candidate plus plants (CPPs) in jatropha (Jatropha curcas). Pakistan Journal of Agricultural Sciences. 53:585-592.

Baydar, N. G., H. Baydar and Debener, T. 2004. Analysis of genetic relationships among Rosa damascena plants grown in Turkey by using AFLP and microsatellite markers. Journal of Biotechnology 111.263-267. Cairns, T., 1993. Modern Roses 10. American Rose Society, Shreveport.

Cairns, T., 1993. Modern Roses 10. American Rose Society, Shreveport.

Crespel, L., and Mouchotte, J. 2003. Methods of cross breeding. In: Roberts, A., Debener, T., Gudin, S. (Eds.), Encyclopedia of Rose Science. Elsevier Science, Oxford, pp. 30-33.

De, R. N., J. N. Reddy, A. V. S. Rao and Mohant, K. K. 1992. Genetic divergence in early rice under two situations. Indian J. Genet. Pl. Br. 52: 225- 229.

Debener, T., 1999. Genetic analysis of horticulturally important morphological and physiological characters in diploid roses. Gartenbauwissenschaft. 64, 1420.

Debener, T., and Mattiesch, L. 1998. Effective pairwise combination of long primers for RAPD analyses in roses. Plant Breeding 117, 147-151.

Doyle,J. J., and Doyle, J. L. 1990. Isolation of plant DNA from fresh tissue. Focus 12: 13-15.

Dugo, M. L., Z. Satovic, T. Millan, J. I. Cubero, D. Rubiales, A. Cabrera and Torres, A. M. 2005. Genetic mapping of QTLs controlling horticultural traits in diploid roses. Theor. Appl. Genet.,111:511-520.
Fairbrother, F., 1965. Roses, Panguin, Great Britain.

Kaur, N., I. Sharma, R. K. Sharma, V. Singh and Ahuja, P. S. 2007. Molecular evaluation and micropropagation of field selected elites of $R$. damascene. General and Applied Plant Physiology 33(3-4): 171-186.

Kim, Y., and Byrne, D. H. 1994. Biosystematical classification of genus Rosa using isozyme polymorphism (abstract). Horticulture Science 29:483.

Kruessmann, G., 1981. The Complete Book of Roses. Timber Press, Portland.

Martins, W. S., D. César, S. Lucas, Kelligton Fabricio de Souza Neves, John Bertioli D. 2009. WebSat - A web software for microsatellite marker development. Biomedical Informatics Publishing Group, 3(6): 282-283.

Murray, M. G., and Thompson, W. F. 1980. Rapid isolation of high molecular weight plant DNA. Nucleic Acids Research 8(16): 4321- 25.

Nilsson, O., 1997. Rosa. In: Davis PH, editor. Flora of Turkey and the East Aegean Islands, Vol. 4. Edinburgh, UK: Edinburgh University Press, pp. 106128.

Panwar, S., K. Singh, K. P. Sonah, R. K. Deshmukh, B. Namita, K. V. Prasad and Sharma, T. 2015. Molecular fingerprinting and assessment of genetic diversity in rose (Rosa $\times$ hybrida). Indian J. Biotechnol. 14: 518-524.

Phillips, R., and Rix, M. 1988. Roses. Random House, pp 224.

Quest Ritson, C., and Quest Ritson, B. 2003. The American Rose Society Encyclopedia of Roses, p 44. D K Publishing Inc., New York.

Rajapakse, S., D. H. Byrne,L. Zhang, N. Anderson, K. Arumuganathan, and Ballard, R. E.2001. Two genetic linkage maps of tetraploid roses. Theoretical and Applied Genetics, 103: 575-583. 
Rajeshbabu, P. M., B. Gopalakrishnan Janarthanan and Sekar, T. 2014. An efficient and rapid generation protocol for 27 micropagation of Rose bourboniana from nodal explants. Int. J. of Current Biotechnology; 2(1):24-29.

Rohlf, F. J., 1989. NTSYS-PC Numerical Taxonomy and Multivariate Analysis System. Exeter Publishing Setauket, NY, pp. 22-28.

Saghai-Maroof, M. A., K. M. Soliman, R. A. Jorgensen and Allard, R.W. 1984. Ribosomal DNA spacer-length polymorphisms in barley: Mendelian inheritance, chromosomal location, and population dynamics. Proceedings of the National Academy of Sciences USA. 8: 8014- 18.

Singh, S. P., 1991. Genetic divergence and canonical analysis in hyacinth bean (Dolichos lablab). J. Genet. Plant. Breed. 45: 7-12.

Singh, S. P., and Shukla, S.1998. Genetic divergence in relation to breeding for fatty acids in opium poppy (Papaver somniferum L.). Journal of Genetics and
Breeding 52: 301-306.

Sasikumar, K., S. K. Singh, T. Mohapatra and Prasad, K. V. 2007. Characterization of rose cultivars and species by DNA fingerprinting. Indian Journal of Horticulture 64(4): 8794.

Ogras T., E.K. Bastanlar, O. K. Metin, I. Kandemir and Ozçelik, H. 2017. Assessment of genetic diversity of rose genotypes using ISSR markers. Turkish Journal of Botany 41:347-355.

Vavilov, N. I., 1926. Studies on the origin of cultivated plants. Bull. Appl. Bot. 16: 2.

Yan, Z., C. Denneboom, A. Hattendorf, O. Dolstra, T. Debener, P. Stamand Visser, P.B. 2005. Construction of an integrated map of rose with AFLP, SSR, PK, RGA, RFLP, SCAR and morphological markers. Theor. Appl. Genet., 110:766777.

Zhang, L. H., D. H. Byrne, R. E. Ballar and Rajapakse, S. 2006. Microsatellite marker development in rose and its application in tetraploid mapping. J. Am. Soc. Hort. Sci. 131, 380-387.

\section{How to cite this article:}

Tanay Joshi, Santosh Kumar, Mohan Bhimte and Lakhapati Singh. 2020. Expressed Sequence Tag-Simple Sequence Repeat (EST-SSR) Marker Resources for Genetic Diversity Analysis in Different Varieties of Roses (Rosa spp.). Int.J.Curr.Microbiol.App.Sci. 9(05): 1721-1730. doi: https://doi.org/10.20546/ijcmas.2020.905.193 